\title{
Methane Production by Mixed Ruminal Cultures Incubated in Dual-Flow Fermentors
}

\author{
J-S. Eun, ${ }^{1, \star}$ V. Fellner, ${ }^{1,} \dagger$ and M. L. Gumpertz ${ }^{2}$ \\ ${ }^{1}$ Department of Animal Science and \\ ${ }^{2}$ Department of Statistics, North Carolina State University, Raleigh 27695
}

\begin{abstract}
This study evaluated the effects of dilution rate and forage-to-concentrate ratio on gas production by rumen microbes. Continuous cultures were used to monitor methane production at three liquid dilution rates $(3.2$, 6.3 , or $12.5 \% / \mathrm{h}$ ) and three forage-to-concentrate ratios $(70: 30,50: 50$, or $30: 70)$. Filtered ruminal contents were allowed $6 \mathrm{~d}$ of adaptation to diets followed by $7 \mathrm{~d}$ of data collection. Forage consisted of pelleted alfalfa and the concentrate mix included ground corn, soybean meal, and a mineral and vitamin premix. The experiment was replicated in a split-plot design. Total volatile fatty acid production averaged $58.0 \mathrm{mmol} / \mathrm{d}$ and was not affected by treatment. Molar proportion of acetate increased with increasing forage-to-concentrate ratio. Molar proportion of propionate tended to decrease at dilution rate of $12.5 \% / \mathrm{h}$ and increased with the medium and low forage-to-concentrate ratio. Culture $\mathrm{pH}$ tended to be greater at a dilution rate of $12.5 \% / \mathrm{h}$. Methane production that was calculated from stoichiometric equations was not affected by treatments. However, methane production based on methane concentration in fermentor headspace resulted in an interaction effect of treatments. Stoichiometric equations underestimated methane output at higher dilution rates and with high forage diets. Total diet fermentability was lowest at dilution rate of $3.2 \% / \mathrm{h}$. Increasing dilution rates increased microbial yield; increasing the proportion of concentrate improved microbial efficiency. Dilution rate and forage-to-concentrate ratio altered the partition of substrate by microbes. Methane production based on actual concentrations differed from values estimated using stoichiometry of end-product appearance.
\end{abstract}

(Key words: continuous culture, methane production, stoichiometric equation, microbial energetics)

\footnotetext{
Received January 22, 2003.

Accepted July 18, 2003.

Corresponding author: V. Fellner; e-mail: vivek_fellner@ncsu.edu. *Present address: Agriculture and Agri-Food Canada, Research Centre, 5403 1st Ave. South, PO Box 3000, Lethbridge, AB T1K 4B1, Canada.

$\dagger$ To whom correspondence should be addressed.
}

\begin{abstract}
Abbreviation key: A:P = acetate-to-propionate, F:C = forage-to-concentrate ratio, $\mathbf{H F}=$ high forage (70 forage:30 concentrate), $\mathbf{L F}=$ low forage (30 forage:70 concentrate), $\mathbf{M F}=$ medium forage (50 forage:50 concentrate).
\end{abstract}

\section{INTRODUCTION}

Volatile fatty acids, $\mathrm{CO}_{2}$, and methane $\left(\mathrm{CH}_{4}\right)$ are the major end products of anaerobic fermentation of feeds in the rumen. Stoichiometric equations relating substrate degradation to VFA and gas production have been developed and are commonly used to estimate digestibility of ruminant feeds (Wolin, 1960; Russell and Baldwin, 1979; Menke et al., 1979; Van Soest, 1994). Total gas production is increasingly used as a measure of the fermentation potential of feeds (Beuvink and Spoelstra, 1992; Pell and Schofield, 1993). Because the composition of the end products influences the amount of gas produced, a close relationship between the two has been reported (Naga and Harmeyer, 1975; Taya et al., 1980; Menke and Steingass, 1988). However, rate of fermentation can vary with carbohydrate fraction; rapidly fermenting carbohydrates may not always result in larger amounts of total gas production (Beuvink and Spoelstra, 1992). Also, total gas yield can vary considerably due to the incorporation of carbons into microbial mass as well as the different metabolic pathways by which carbohydrate fractions can be degraded by rumen microbes (Krishnamoorthy et al., 1991; Beuvink and Spoelstra, 1992; Van Soest, 1994). The relationship between microbial biomass and gas yield can vary also with growth conditions (Krishnamoorthy et al., 1991; Blümmel et al., 1997). With shortduration incubation studies, fermentation rate as measured by gas production has been used as an index of net growth yield of rumen microorganisms (El-Din and El-Shazly, 1969). Extending the period of incubation reduced net growth of microorganisms even though gas production continued to increase (Raab, 1980). Increased lysis of microbial cells as a consequence of substrate exhaustion and uncoupled fermentation may contribute to reduced net growth at longer incubation times (Van Nevel and Demeyer, 1977). Changes in mi- 
crobial yield or metabolism may alter the relationship between substrate digestion and gas production and could affect the estimation of digestion rate from gas measurements (Doane et al., 1997). Previous studies do not make any distinction between $\mathrm{CO}_{2}$ and $\mathrm{CH}_{4}$ and assume that the latter arises directly from the former (Beuvink and Spoelstra, 1992; Theodorou et al., 1998). There is evidence to suggest that more than one fermentation metabolite may be used for the production of $\mathrm{CH}_{4}$ (Miller, 1995). Methanogens have been shown to have variable affinities for hydrogen and are capable of altering their growth rates depending upon the availability of hydrogen and $\mathrm{CO}_{2}$ (Morgan et al., 1997). No study has compared actual $\mathrm{CH}_{4}$ production in mixed ruminal cultures to estimates based on stoichiometric equations. In addition, the generation of microbial biomass can be a sink for reducing equivalents and, if ignored, it can result in the overprediction of $\mathrm{CH}_{4}$ output (Wolin, 1960; Hungate, 1967).

The objective of the present study was to determine $\mathrm{CH}_{4}$ production by mixed ruminal microbes under different dilution rates and dietary treatments. Direct measurements of $\mathrm{CH}_{4}$ concentration in fermentor headspace were compared with estimates of $\mathrm{CH}_{4}$ production based on stoichiometric equations.

\section{MATERIALS AND METHODS}

\section{Incubation Conditions}

A mature lactating Holstein cow fitted with a rumen cannula was fed a diet consisting of $63 \%$ roughage and $37 \%$ concentrate. Grab samples of ruminal contents were taken from various sites within the reticulo-rumen, filtered through double-layered cheesecloth, and transported to the laboratory in sealed, preheated containers. In the laboratory, contents from the containers were filtered again through double-layered cheesecloth into a large, wide-mouth beaker and mixed thoroughly before pouring into the fermentors. The preparation time of the ruminal contents in the laboratory did not exceed $15 \mathrm{~min}$. Approximately $700 \mathrm{ml}$ of the strained ruminal fluid was transferred into each of three fermentors with a continuous dual-flow system (Teather and Sauer, 1988). The design of the fermentors allows for natural stratification of contents similar to the way it occurs in the rumen. The stratification of the fermentor contents is accomplished with the presence of a glass "T" that serves as the fermentor overflow. The entrance to the outlet "T" is near the bottom of the suspended particle phase, which allowed for differential liquid and solid turnover rates. The presence and maintenance of the "mat" in the cultures and the relatively slower rate at which culture contents are stirred (10 to $12 \mathrm{rpm}$ ) in these fermentors allow protozoal populations to remain in cultures over extended periods. We did not directly measure protozoal populations in the present study. However, protozoa were visually present in the fermentors for the duration of the experiment. Following inoculation, protozoa were consistently discernible as large white bands within the fermentors. Over a 1to 2-d period, the protozoa tended to localize either at the base or the bottom of the overflow port, areas that seemed to have the slowest turnover rate. The close association between the methanogens and protozoa and the sustained production of methane at high levels in these fermentors for extended periods of operation also suggests that protozoa are maintained during the duration of the study. Several hours prior to the addition of the ruminal fluid, the system was purged with $\mathrm{CO}_{2}$ gas. To displace $\mathrm{O}_{2}$ and maintain anaerobic conditions in the vessels, the rate of $\mathrm{CO}_{2}$ flow through the fermentors was fixed at $20 \mathrm{~mL} / \mathrm{min}$ throughout the experiments. A circulating water bath was used to maintain the temperature of the fermentors at $39^{\circ} \mathrm{C}$. Continuous stirring of fermentor contents was achieved with the aid of a central paddle set at a speed of $10 \mathrm{rpm}$. Artificial saliva was prepared as described by Slyter et al. (1966) and delivered continuously at $0.73 \mathrm{~mL} / \mathrm{min}$. Liquid turnover rate was increased or decreased by adjusting the saliva flow rate as described below.

\section{Dietary Treatments and Dilution Rates}

Experimental diets consisted of 3 forage-to-concentrate $(\mathbf{F}: \mathbf{C})$ ratios: high forage $(\mathbf{H F}), 70: 30$; medium forage (MF), 50:50; and low forage (LF), 30:70. The forage comprised $100 \%$ pelleted alfalfa $(16.5 \% \mathrm{CP})$ and the concentrate $(13.1 \% \mathrm{CP})$ consisted of $81.4 \%$ ground corn, $10.4 \%$ soybean meal ( $48 \% \mathrm{CP}), 2.1 \%$ bentonite, $1.5 \%$ sodium bicarbonate, $1.3 \%$ phosphate, $1.1 \%$ limestone, $1.0 \%$ soybean oil, $1.0 \%$ salt, and $0.2 \%$ vitaminmineral premix. The chemical composition of dietary treatments is as follows: HF: $31.8 \% \mathrm{NDF}, 15.5 \% \mathrm{CP}$, 67.8\% TDN; MF: $25.2 \% \mathrm{NDF}, 14.8 \% \mathrm{CP}, 72.8 \% \mathrm{TDN}$, and LF: $18.6 \% \mathrm{NDF}, 14.1 \% \mathrm{CP}$, and $77.7 \%$ TDN. The digestible energy content of the diets was 3.0, 3.2, and $3.4 \mathrm{Mcal} / \mathrm{kg}$ and was estimated based on NRC (1989) values. A total of $12.8,12.9$, or $13.0 \mathrm{~g}$ DM of the diet was added daily in two equal amounts to the fermentor with $\mathrm{HF}, \mathrm{MF}$, or LF diets. All fermentors were stabilized on the HF diet for $2 \mathrm{~d}$ (stabilization period). Preliminary results have indicated that microbial VFA, $\mathrm{CH}_{4}$, and $\mathrm{pH}$ reach a stable steady-state level within $2 \mathrm{~d}$ following the addition of ruminal contents into the fermentors. At the end of $d 2$, one fermentor was maintained on the HF diet, and the other two received the MF diet for an additional $2 \mathrm{~d}$. On $\mathrm{d} 5$, one of the two fermentors receiving the MF diet was switched to the LF diet and was 
allowed to stabilize for an additional $2 \mathrm{~d}$. By the end of d 6, all three fermentors had been stabilized for at least $2 \mathrm{~d}$ on the respective dietary treatments. Data were collected from d 7 to 13 (treatment period).

The effect of the 3 diets was tested at three different dilution rates of $0.032,0.063$, and $0.125 / \mathrm{h}$, approximating $0.8,1.5$, and 3.0 volume turnovers per day. These dilution rates were chosen to cover the physiological range of fluid turnover rates that are typically observed in vivo. Throughout all experiments, fermentors were allowed to stabilize for $2 \mathrm{~d}$ at a saliva flow rate of 0.73 $\mathrm{mL} / \mathrm{min}$. Following stabilization, saliva flow rate was either maintained at $0.73 \mathrm{~mL} / \mathrm{min}$ resulting in a fractional dilution rate of $6.3 \% / \mathrm{h}$ or it was adjusted, beginning on $\mathrm{d} 3$, to obtain fractional dilution rate of 3.2 or $12.5 \% / \mathrm{h}(0.37$ or $1.46 \mathrm{~mL} / \mathrm{min}$, respectively $)$.

\section{Sampling and Analyses}

Five milliliters of thoroughly mixed fermentor contents was taken $2 \mathrm{~h}$ after the a.m. and p.m. feeding daily for $7 \mathrm{~d}$ and analyzed for VFA by GLC (model CP3380; Varian, Walnut Creek, CA) using a fused silica capillary column (Nukol; Supelco Inc., Bellefonte, PA) and for ammonia- $\mathrm{N}\left(\mathrm{NH}_{3}-\mathrm{N}\right)$ using a colorimetric assay (Beecher and Whitten, 1970). Production of $\mathrm{NH}_{3}-\mathrm{N}$ was calculated as:

$$
\begin{gathered}
\mathrm{NH}_{3}-\mathrm{N}(\mathrm{g} / \mathrm{d})=\left(\mathrm{NH}_{3}-\mathrm{N} \text { concentration, } \mathrm{mg} / \mathrm{ml}\right. \\
\quad \times \text { fermentor volume }(700 \mathrm{ml}) \\
\times \text { turnover rate of fermentor } / 1,000 .
\end{gathered}
$$

Ten microliters of headspace gas samples from the fermentor was drawn into a gas-tight syringe (Hamilton Co., Reno, NV) and analyzed for $\mathrm{CH}_{4}$ by GLC (model CP-3800; Varian) using a stainless steel column packed with Molsieve 5A 45/60 mesh (Supelco Inc.). The pH of the ruminal cultures was monitored continuously and recorded when samples for $\mathrm{CH}_{4}$ were taken.

Assuming that carbohydrates (hexoses) are the major source of VFA in the rumen, partitioning of substrate use was expressed as the amount of substrate fermented to VFA, gas $\left(\mathrm{CH}_{4}+\mathrm{CO}_{2}\right.$ direct and indirect), or microbial biomass. The direct source of $\mathrm{CO}_{2}$ is the fermentation of glucose by various pathways yielding VFA, ATP, and $\mathrm{CO}_{2}$. Because the in vitro methods use bicarbonate-based buffering solutions, $\mathrm{CO}_{2}$ is released into the gas phase as VFA enter the medium (Beuvink and Spoelstra, 1992). This source of $\mathrm{CO}_{2}$ is considered as indirect $\mathrm{CO}_{2}$ production. The amount of substrate fermented to VFA, $\mathrm{CH}_{4}$, and $\mathrm{CO}_{2}$ was calculated based on the moles of individual VFA produced, daily methane output, and $\mathrm{CO}_{2}$ released from fermentation and buffer addition (Wolin, 1960; Van Soest, 1994; Blümmel et al.,
1997). Total moles of ATP production were estimated by assigning 2,3 , and 3, moles of ATP per mol of acetic, propionic, and butyric acids, respectively, and $1 \mathrm{~mol}$ of ATP per mol of $\mathrm{CH}_{4}$ (Groot et al., 1998). Microbial efficiency was reported to average $11.7 \mathrm{~g}$ of cells $/ \mathrm{mol}$ of ATP and was not affected significantly by the energy concentration in mixed cultures of ruminal organisms (Isaacson et al., 1975). However, changing dilution rates did affect the efficiency of microbial protein synthesis that was reported to be $7.5,11.6$, and $16.7 \mathrm{~g}$ of cells/mol of ATP at fractional dilution rates of 2,6 , and $12 \% / \mathrm{h}$, respectively (Isaacson et al., 1975). The dilution rates tested in the present study were similar to those used by Isaacson et al. (1975) and, therefore, the yield of microbial biomass per mol ATP $\left(\mathrm{Y}_{\mathrm{ATP}}\right)$ was set to be 7.5, 11.6, and $16.7 \mathrm{mg} / \mathrm{mmol}$ ATP for dilution rates of $3.2,6.3$, and $12.5 \% / \mathrm{h}$, respectively. Also assumed was that $80 \%$ of bacterial components were synthesized from glucose skeletons (Groot et al., 1998). Consequently, microbial biomass from glucose consumption was calculated as:

Microbial biomass $(\mathrm{g} / \mathrm{d})=$

$0.8 \mathrm{Y}_{\text {ATP }}(2$ Acetate, $\mathrm{mmol} / \mathrm{d}+3$ Propionate, $\mathrm{mmol} / \mathrm{d}+3$ Butyrate, $\left.\mathrm{mmol} / \mathrm{d}+\mathrm{CH}_{4}, \mathrm{mmol} / \mathrm{d}\right) / 1,000$

Energy contents of acetate, propionate, butyrate, valerate, isobutyrate, and isovalerate were used to estimate digestible energy. Similarly, energy content of $\mathrm{CH}_{4}$ was used to estimate contribution of energy in $\mathrm{CH}_{4}$ to total digestible energy. In addition to direct measurement of $\mathrm{CH}_{4}$, the production of fermentation gases, $\mathrm{CO}_{2}$ and $\mathrm{CH}_{4}$, and the associated production of $\mathrm{H}_{2} \mathrm{O}$, was calculated using the equation outlined by Wolin (1960) and Blümmel et al. (1997).

\section{Experimental Design and Statistical Analyses}

Within a run, an experimental period lasted $13 \mathrm{~d}$, which included $6 \mathrm{~d}$ for adaptation followed by $7 \mathrm{~d}$ for data collection. Daily values were averaged across the $7 \mathrm{~d}$ within each run. A single run was composed of 3 fermentors that were inoculated simultaneously with ruminal contents obtained from the same cow. Each fermentor was randomly assigned to one of 3 diets with different $F: C$ ratios. Each run was replicated $(n=2)$ at each of the three dilution rates.

Data were analyzed using the GLM procedure of SAS (SAS Inst. Inc., Cary, NC). Split-plot design was used with dilution rate as whole plot and F:C ratio as subplot. The model used is described by:

$$
\mathrm{Y}_{\mathrm{ijk}}=\mu+\mathrm{DR}_{\mathrm{i}}+\operatorname{Run}_{\mathrm{j}}\left(\mathrm{DR}_{\mathrm{i}}\right)+\mathrm{FC}_{\mathrm{k}}+\mathrm{DR}_{\mathrm{i}} \times \mathrm{FC}_{\mathrm{k}}+\mathrm{e}_{\mathrm{ijk}}
$$


Table 1. Concentration and production of VFA as affected by dilution rate (DR) and forage-to-concentrate ratio (F:C). ${ }^{1}$

\begin{tabular}{|c|c|c|c|c|c|c|c|c|c|c|c|c|c|}
\hline \multirow[b]{3}{*}{ VFA } & \multicolumn{9}{|c|}{$\mathrm{DR}, \% / \mathrm{h}$} & \multirow[b]{3}{*}{$\mathrm{SE}$} & \multirow{2}{*}{\multicolumn{3}{|c|}{ Significance of effect }} \\
\hline & \multicolumn{3}{|c|}{3.2} & \multicolumn{3}{|c|}{6.3} & \multicolumn{3}{|c|}{12.5} & & & & \\
\hline & $\mathrm{HF}$ & MF & $\mathrm{LF}$ & $\mathrm{HF}$ & MF & $\mathrm{LF}$ & $\mathrm{HF}$ & $\mathrm{MF}$ & $\mathrm{LF}$ & & DR & $\mathrm{F}: \mathrm{C}$ & $\mathrm{DR} \times \mathrm{F}: \mathrm{C}^{2}$ \\
\hline Total, $\mathrm{m} M$ & 97.7 & 100.4 & 104.0 & 56.9 & 63.2 & 59.5 & 27.3 & 25.7 & 29.6 & 2.69 & 0.01 & NS4 & NS \\
\hline \multicolumn{14}{|l|}{ Individual, mol/100 mol } \\
\hline Acetate (A) & 53.0 & 52.7 & 50.0 & 54.9 & 48.6 & 44.6 & 60.6 & 54.4 & 49.9 & 2.07 & NS & 0.01 & NS \\
\hline Propionate (P) & 28.9 & 29.8 & 29.4 & 26.1 & 31.2 & 35.5 & 18.7 & 25.2 & 22.4 & 1.64 & 0.07 & 0.03 & NS \\
\hline Isobutyrate & 0.3 & 0.3 & 0.3 & 0.9 & 0.9 & 0.8 & 0.7 & 0.4 & 1.0 & 0.13 & 0.01 & NS & NS \\
\hline Isovalerate & 2.0 & 0.9 & 0.9 & 3.2 & 3.9 & 3.8 & 3.0 & 6.5 & 3.7 & 0.31 & 0.01 & 0.01 & 0.01 \\
\hline A:P ratio & 1.9 & 1.8 & 1.8 & 2.2 & 1.6 & 1.3 & 3.3 & 2.3 & 2.3 & 0.20 & 0.01 & 0.01 & NS \\
\hline $\mathrm{Total}^{3}{ }^{3} \mathrm{mmol} / \mathrm{d}$ & 51.8 & 53.2 & 55.1 & 59.8 & 66.3 & 62.5 & 57.3 & 54.0 & 62.3 & 3.19 & $\mathrm{NS}^{4}$ & NS & NS \\
\hline \multicolumn{14}{|l|}{ Individual ${ }^{3} \mathrm{mmol} / \mathrm{d}$} \\
\hline Acetate & 27.5 & 27.9 & 27.4 & 32.9 & 31.9 & 27.8 & 34.7 & 30.0 & 31.5 & 2.11 & NS & NS & NS \\
\hline Propionate & 14.9 & 16.0 & 16.4 & 15.6 & 20.9 & 22.2 & 10.7 & 13.3 & 13.8 & 1.21 & NS & 0.02 & NS \\
\hline
\end{tabular}

${ }^{1} \mathrm{HF}=$ High forage (70\% forage: $30 \%$ concentrate); $\mathrm{MF}=$ medium forage (50\% forage: $50 \%$ concentrate); $\mathrm{LF}=$ low forage $(30 \%$ forage: $70 \%$ concentrate).

${ }^{2} \mathrm{DR} \times \mathrm{F}: \mathrm{C}=$ Interaction between dilution rate and $\mathrm{F}: \mathrm{C}$ ratio.

${ }^{3}$ Production parameters are based on $1 \mathrm{~L}$ of ruminal cultures.

${ }^{4} \mathrm{NS}=$ Not significant $(P>0.10)$

where

$\mathrm{Y}_{\mathrm{ijk}}=$ individual response variable measured,

$\mu=$ overall mean,

$\mathrm{DR}_{\mathrm{i}}=$ fixed effect of dilution rate ( $\mathrm{i}=1$ to 3 ), $\operatorname{Run}_{\mathrm{j}}\left(\mathrm{DR}_{\mathrm{i}}\right)=$ whole plot error,

$\mathrm{FC}_{\mathrm{k}}=$ fixed effect of $\mathrm{F}: \mathrm{C}$ ratio $(\mathrm{k}=1$ to 3$)$,

$\mathrm{DR}_{\mathrm{i}} \times \mathrm{FC}_{\mathrm{k}}=$ fixed effect of interaction between dilution rate and $\mathrm{F}: \mathrm{C}$ ratio, and

$\mathrm{e}_{\mathrm{ijk}}=$ subplot error.

Dilution rates were compared with the whole plot error term. Forage-to-concentrate ratios and interaction between dilution rate and $\mathrm{F}: \mathrm{C}$ ratio were tested using the subplot error term. Standard errors appropriate for comparisons among different means were calculated as follows (Steel et al., 1997):

for comparing dilution rate:

$$
\operatorname{SE}\left(\overline{\mathrm{y}}_{1 \ldots}-\overline{\mathrm{y}}_{2} . .\right)=\sqrt{\frac{2 M S E_{\text {whole plot }}}{6}}
$$

for comparing $\mathrm{F}: \mathrm{C}$ ratio:

$$
\mathrm{SE}\left(\overline{\mathrm{y}}_{1} \ldots-\overline{\mathrm{y}}_{2} . .\right)=\sqrt{\frac{2 M S E_{\text {subplot }}}{6}}
$$

Comparison of dilution rate and $\mathrm{F}: \mathrm{C}$ ratio means was done by contrast test with Fisher's protected LSD test when the effect of dilution rate or $\mathrm{F}: \mathrm{C}$ ratio $(P \leq 0.10)$ was detected by the model. The level of significance accepted was $P \leq 0.05$ and 0.10 for trend.

\section{RESULTS}

Total VFA concentrations (millimolar) and molar percentages of individual VFA are reported in Table 1. Increasing the dilution rate reduced $(P<0.01)$ the concentration of total VFA. Molar proportion of acetate ranged from 49 to 56 and was not affected by dilution rate. Propionate remained unchanged $(P>0.10)$ when dilution rate increased from 3.2 to $6.3 \% / \mathrm{h}$ but tended to decrease $(P<0.07)$ at $12.5 \% / \mathrm{h}$. The acetate-to-propionate $(\mathbf{A}: \mathbf{P})$ ratio increased $(P<0.01)$ with increasing the dilution rate from 3.2 or 6.3 to $12.5 \% / \mathrm{h}$. Increasing the proportion of concentrate in the diet decreased ( $P$ $<0.01)$ the molar proportion of acetate. Molar proportions of propionate were lowest for the HF diet and increased $(P<0.03)$ for the MF and LF diets. Molar proportions of valerate were similar for the $\mathrm{HF}$ and $\mathrm{MF}$ diets but increased for the LF diet. The A:P ratio was highest for the HF diet and decreased $(P<0.01)$ for the $\mathrm{MF}$ and LF diets.

There were dilution rate $\times \mathrm{F}$ :C interactions for molar percentages of butyrate and isovalerate. At $3.2 \% / \mathrm{h}$, bu- 
Table 2. Ruminal $\mathrm{pH}$, ammonia- $\mathrm{N}\left(\mathrm{NH}_{3}-\mathrm{N}\right)$, and methane $\left(\mathrm{CH}_{4}\right)$ production as affected by dilution rate (DR) and forage-to-concentrate ratio $(\mathrm{F}: \mathrm{C}){ }^{1}$

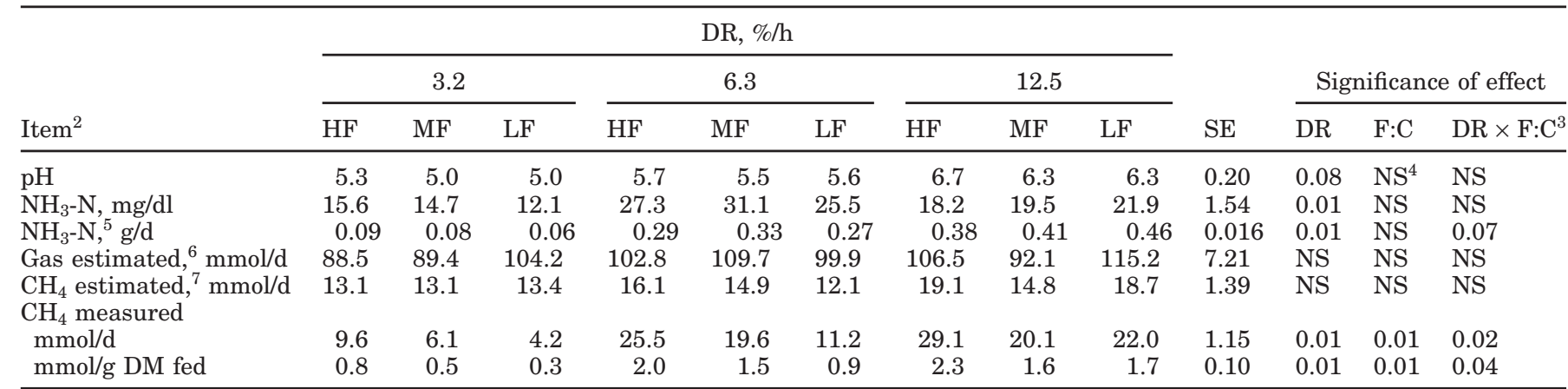

${ }^{1} \mathrm{HF}=$ High forage (70\% forage:30\% concentrate); $\mathrm{MF}=$ medium forage (50\% forage:50\% concentrate); $\mathrm{LF}=$ low forage $(30 \%$ forage: $70 \%$ concentrate).

${ }^{2}$ Production parameters are based on $1 \mathrm{~L}$ of ruminal cultures.

${ }^{3} \mathrm{DR} \times \mathrm{F}: \mathrm{C}=$ Interaction between dilution rate and $\mathrm{F}: \mathrm{C}$ ratio.

${ }^{4} \mathrm{NS}=$ Not significant $(P>0.10)$.

${ }^{5} \mathrm{NH}_{3}-\mathrm{N}(\mathrm{g} / \mathrm{d})=\left(\mathrm{NH}_{3}-\mathrm{N}\right.$ concentration, $\mathrm{mg} / \mathrm{dl} \times$ fermentor volume $(700 \mathrm{ml}) \times$ turnover rate of fermentor $) / 1,000$. Turnover rate of fermentor is $0.8,1.5$, and 3.0 for $3.2,6.3$, and $12.5 \% / \mathrm{h}$, respectively.

${ }^{6}$ Fermentative $\mathrm{CO}_{2}+$ fermentative $\mathrm{CH}_{4}+$ buffering $\mathrm{CO}_{2}$. All gas productions were estimated.

${ }^{7}($ Acetate, $\mathrm{mmol} / \mathrm{d})+(2 \times$ butyrate, $\mathrm{mmol} / \mathrm{d})-\left(\mathrm{CO}_{2}, \mathrm{mmol} / \mathrm{d}\right)$.

tyrate proportion was highest in the LF diet and similar between the MF and $\mathrm{HF}$ diets. When dilution rate was increased to $6.3 \% / \mathrm{h}$, there was no difference in butyrate concentration between $\mathrm{F}: \mathrm{C}$ ratios. At a dilution rate of $12.5 \% / \mathrm{h}$, molar proportions of butyrate were highest for the LF diet and lowest for the MF diet with the HF diet being intermediate. Molar proportions of isovalerate were higher in the HF diet when compared with either the MF or LF diets at a dilution rate of $3.2 \% / \mathrm{h}$. At a dilution rate of $6.3 \% / \mathrm{h}$, isovalerate was numerically higher for both the MF and LF diets. Increasing the dilution rate to $12.5 \% / \mathrm{h}$ increased isovalerate in ruminal cultures receiving $\mathrm{MF}$ and was higher compared with both the HF and LF diets.

Daily production of total VFA ( $\mathrm{mmol} / \mathrm{d})$ was not affected by dilution rate or $\mathrm{F}: \mathrm{C}$ ratio (Table 1 ). The rate of production of acetate and propionate did not change as a result of changing the dilution rate. Increasing dilution rate decreased $(P<0.01)$ the production of valerate, which was consistent with lower concentrations in ruminal cultures. There were interactions for butyrate, isobutyrate, and isovalerate. Daily output of butyrate followed the same trend as the molar proportions of butyrate in the cultures. The LF diet resulted in the highest production of butyrate at dilution rates of 3.2 and $12.5 \% / \mathrm{h}$. The MF and HF diets were similar at 3.2 and $6.3 \% / \mathrm{h}$, but increasing dilution rate to $12.5 \% /$ $\mathrm{h}$ increased butyrate production in cultures receiving HF compared with the MF diet. Daily output of isobutyrate was very low across all $\mathrm{F}: \mathrm{C}$ ratios at dilution rate of $3.2 \% / \mathrm{h}$. Increasing dilution rate to $6.3 \% / \mathrm{h}$ increased isobutyrate production for all $\mathrm{F}: \mathrm{C}$ treatments; the in- crease was greater for cultures receiving the MF diet. At dilution rate of $12.5 \% / \mathrm{h}$, rate of isobutyrate production increased even further for the LF diet and decreased for both the MF and HF diets. The effect of dilution rate and $\mathrm{F}: \mathrm{C}$ ratio on the rate of isovalerate production was similar to changes observed in molar proportions.

Data for $\mathrm{pH}, \mathrm{NH}_{3}-\mathrm{N}$, and gas production $\left(\mathrm{CO}_{2}\right.$ and $\left.\mathrm{CH}_{4}\right)$ are summarized in Table 2. Ruminal culture $\mathrm{pH}$ did not change $(P>0.10)$ when dilution rates were increased from 3.2 to $6.3 \% / \mathrm{h}(5.08$ and 5.55 , respectively). Increasing dilution rate to $12.5 \% / \mathrm{h}$ tended to increase $(P<0.08)$ culture $\mathrm{pH}$, which averaged 6.40. Concentration of $\mathrm{NH}_{3}-\mathrm{N}$ was highest at $6.3 \% / \mathrm{h}$ and lowest at $3.2 \% / \mathrm{h}$, with $12.5 \% / \mathrm{h}$ being intermediate. There were no effects of $\mathrm{F}: \mathrm{C}$ on $\mathrm{pH}$ and concentration of $\mathrm{NH}_{3}$ $\mathrm{N}$. There was a tendency for dilution rate $\times \mathrm{F}: \mathrm{C}$ interaction for the daily output $(\mathrm{g} / \mathrm{d})$ of $\mathrm{NH}_{3}-\mathrm{N}(P<0.07)$. Increasing the dilution rate resulted in an increase in the production of $\mathrm{NH}_{3}-\mathrm{N}$. At 3.2 and $6.3 \% / \mathrm{h}, \mathrm{F}: \mathrm{C}$ ratio did not seem to affect ammonia production, but increasing dilution rate to $12.5 \% / \mathrm{h}$ increased ammonia output for the LF diet compared with the MF and HF diets.

There was no effect of either dilution rate or $\mathrm{F}: \mathrm{C}$ ratio on methane production $(\mathrm{mmol} / \mathrm{d})$ that was calculated from stoichiometric equations (Table 2). Based on actual measurements, however, there was an interaction for methane output. At each dilution rate, methane output was highest for the HF diet (Table 2). At dilution rate of $3.2 \% / \mathrm{h}$, methane output was similar for the MF and $\mathrm{LF}$ diets, but, at $6.3 \% / \mathrm{h}$, cultures receiving the $\mathrm{MF}$ diet had higher amounts of daily methane production compared with those receiving the LF diet. Increasing 
Table 3. Amount of substrate used for fermentation end products and microbial growth as affected by dilution rate (DR) and forage-toconcentrate ratio (F:C). ${ }^{1}$

\begin{tabular}{|c|c|c|c|c|c|c|c|c|c|c|c|c|c|}
\hline \multirow[b]{2}{*}{ Item } & \multicolumn{9}{|c|}{$\mathrm{DR}, \% / \mathrm{h}$} & \multirow[b]{2}{*}{ SE } & \multicolumn{3}{|c|}{ Significance of effect } \\
\hline & $\mathrm{HF}$ & MF & $\mathrm{LF}$ & $\mathrm{HF}$ & $\mathrm{MF}$ & $\mathrm{LF}$ & $\mathrm{HF}$ & MF & $\mathrm{LF}$ & & $\mathrm{DR}$ & $\mathrm{F}: \mathrm{C}$ & $\mathrm{DR} \times \mathrm{F}: \mathrm{C}^{2}$ \\
\hline DM fed, g/d & 12.8 & 12.9 & 13.0 & 12.8 & 12.9 & 13.0 & 12.8 & 12.9 & 13.0 & & & & \\
\hline \multicolumn{14}{|l|}{ Substrate used, g/d } \\
\hline For VFA 4 & 3.3 & 3.4 & 4.2 & 3.8 & 4.2 & 4.0 & 3.7 & 3.3 & 4.0 & 0.29 & $\mathrm{NS}^{3}$ & NS & NS \\
\hline For gas $^{5}$ & 1.9 & 1.8 & 2.0 & 2.2 & 2.3 & 2.0 & 2.5 & 2.0 & 2.7 & 0.16 & 0.02 & NS & NS \\
\hline Fermentability, $\%^{8}$ & 48.0 & 48.4 & 57.3 & 60.2 & 65.0 & 59.6 & 66.9 & 58.6 & 72.3 & 4.30 & 0.03 & NS & NS \\
\hline \multicolumn{14}{|l|}{ Microbial synthesis } \\
\hline$g / d^{9}$ & 0.79 & 0.81 & 0.98 & 1.39 & 1.54 & 1.45 & 1.96 & 1.78 & 2.16 & 0.104 & 0.01 & NS & NS \\
\hline g DM/kg DM fermented ${ }^{10}$ & 132.7 & 133.5 & 136.4 & 189.2 & 193.0 & 196.6 & 243.4 & 250.8 & 243.9 & 1.41 & 0.01 & 0.02 & 0.05 \\
\hline
\end{tabular}

${ }^{1} \mathrm{HF}=$ High forage $(70 \%$ forage: $30 \%$ concentrate $) ; \mathrm{MF}=$ medium forage (50\% forage:50\% concentrate); LF = low forage $(30 \%$ forage: $70 \%$ concentrate).

${ }^{2} \mathrm{DR} \times \mathrm{F}: \mathrm{C}=$ Interaction between dilution rate and $\mathrm{F}: \mathrm{C}$ ratio.

${ }^{3} \mathrm{NS}=$ Not significant $(P>0.10)$.

${ }^{4}($ Acetate, $\mathrm{mol} / \mathrm{d} \times 60.05)+($ Propionate, $\mathrm{mol} / \mathrm{d} \times 74.08)+($ butyrate, $\mathrm{mol} / \mathrm{d} \times 88.10)$.

${ }^{5}$ Substrate used for $\left(\mathrm{CO}_{2}, \mathrm{~mol} / \mathrm{d} \times 44\right)+\left(\mathrm{CH}_{4}, \mathrm{~mol} / \mathrm{d} \times 16\right)+\left(2 \mathrm{H}_{2} \mathrm{O}, \mathrm{mol} / \mathrm{d} \times 36\right)$.

${ }^{6}$ Substrate used for microbial biomass $=\operatorname{ATP}(\mathrm{mmol}) \times \mathrm{Y}_{\mathrm{ATP}}(7.5,11.6$, and $16.7 \mathrm{mg}$ for 3.2, 6.3, and 12.5\%/h, respectively).

${ }^{7}$ Substrate used for VFA, $\mathrm{CO}_{2}+\mathrm{CH}_{4}+2 \mathrm{H}_{2} \mathrm{O}$, and microbial biomass.

${ }^{8}$ Total substrate fermented expressed as a percentage of DM fed.

${ }^{9}$ Microbial biomass $(\mathrm{g} / \mathrm{d})=\left(\left(\left(0.8 \times \mathrm{Y}_{\mathrm{ATP}}\left((2 \times\right.\right.\right.\right.$ Acetate, $\mathrm{mmol} / \mathrm{d})+(3 \times$ propionate, $\mathrm{mmol} / \mathrm{d})+(3 \times$ butyrate, $\left.\left.\left.\mathrm{mmol} / \mathrm{d})+\left(\mathrm{CH}{ }_{4}, \mathrm{mmol}^{\mathrm{d}}\right)\right)\right)\right) /$ $1000) . \mathrm{Y}_{\mathrm{ATP}}$ is $7.5,11.6$, and $16.7 \mathrm{mg}$ for $3.2,6.3$, and $12.5 \% / \mathrm{h}$, respectively.

${ }^{10}$ Microbial growth efficiency $(\mathrm{g} \mathrm{DM} / \mathrm{kg}$ DM fermented $)=(($ microbial biomass, $\mathrm{g} / \mathrm{DM}$ fermented, g $) \times 1000)$.

the dilution rate to $12.5 \% / \mathrm{h}$ did not increase methane output for the MF diet, but there was a substantial increase for the LF diet, which was numerically higher compared with the MF diet. When expressed as mmol of methane produced per gram of DM fed, the effects of dilution rate and F:C were similar to the total daily production rates described above.

The amount of substrate used for gas $\left(\mathrm{CH}_{4}+\right.$ direct and indirect $\left.\mathrm{CO}_{2}\right)$ was not affected $(P>0.10)$ by either dilution rate or F:C (Table 3). The amount of substrate used for microbial biomass was $1.07 \mathrm{~g} / \mathrm{d}$ at the lowest dilution rate and increased $(P<0.01)$ to 1.83 and 2.46 $\mathrm{g} / \mathrm{d}$ at dilution rate of 6.3 and $12.5 \% / \mathrm{h}$, respectively (Table 3). Based on the substrate used for VFA, gas, and microbial biomass, total diet fermentability was similar $(P>0.10)$ at dilution rates of 6.3 and $12.5 \% / \mathrm{h}$ (61.6 and $65.9 \%)$ but decreased $(P<0.04)$ when dilution rate was decreased to $3.2 \% / \mathrm{h}(51.2 \%)$. The $\mathrm{F}: \mathrm{C}$ ratios did not affect $(P>0.10)$ total diet fermentability.

Microbial yields increased $(P<0.01)$ with increasing dilution rate and averaged $0.86,1.46$, and $1.97 \mathrm{~g} / \mathrm{d}$ at dilution rates of $3.2,6.3$, and $12.5 \% / \mathrm{h}$, respectively (Table 3). Increasing the proportion of concentrate in the diet did not affect microbial yield $(P>0.10)$ but improved $(P<0.02)$ microbial growth efficiency (Table 3$)$. There was an interaction between dilution rate and $\mathrm{F}: \mathrm{C}$ for microbial efficiency. At a dilution rate of $6.3 \% / \mathrm{h}$, microbial growth efficiency in cultures receiving LF diet was numerically higher than cultures receiving $\mathrm{MF}$ diet, but increasing dilution rate to $12.5 \% / \mathrm{h}$ resulted in numerically higher efficiency of microbial growth in fermentors receiving MF diet compared with those receiving the LF diet.

The amount of energy produced daily in the form of VFA and as a percentage of digestible energy fed was not affected by dilution rate (Table 4). A higher proportion of concentrate tended to increase $(P<0.08)$ the amount of energy (kcal/d) captured in VFA due primarily to the increased digestible energy fed. The VFA energy as a percentage of digestible energy fed was not affected by F:C ratio. There was an interaction for the amount of energy released in $\mathrm{CH}_{4}(P<0.01)$. At dilution rates of 3.2 and $6.3 \% / \mathrm{h}$, cultures receiving the $\mathrm{LF}$ diet had the lowest rate of methane production; however, increasing dilution rate to $12.5 \% / \mathrm{h}$ resulted in the $\mathrm{MF}$ diet having the lowest methane output.

\section{DISCUSSION}

Altering liquid turnover rates had no effect on daily production of total VFA or in the proportion and production of acetate by ruminal cultures. These results are similar to those reported by Isaacson et al. (1975) and Hoover et al. (1984). Molar proportion of propionate 
Table 4. Amount of digestible energy (DE) partitioned into VFA and methane $\left(\mathrm{CH}_{4}\right)$ obtained by actual measurement as affected by dilution rate (DR) and forage-to-concentrate ratio (F:C). ${ }^{1}$

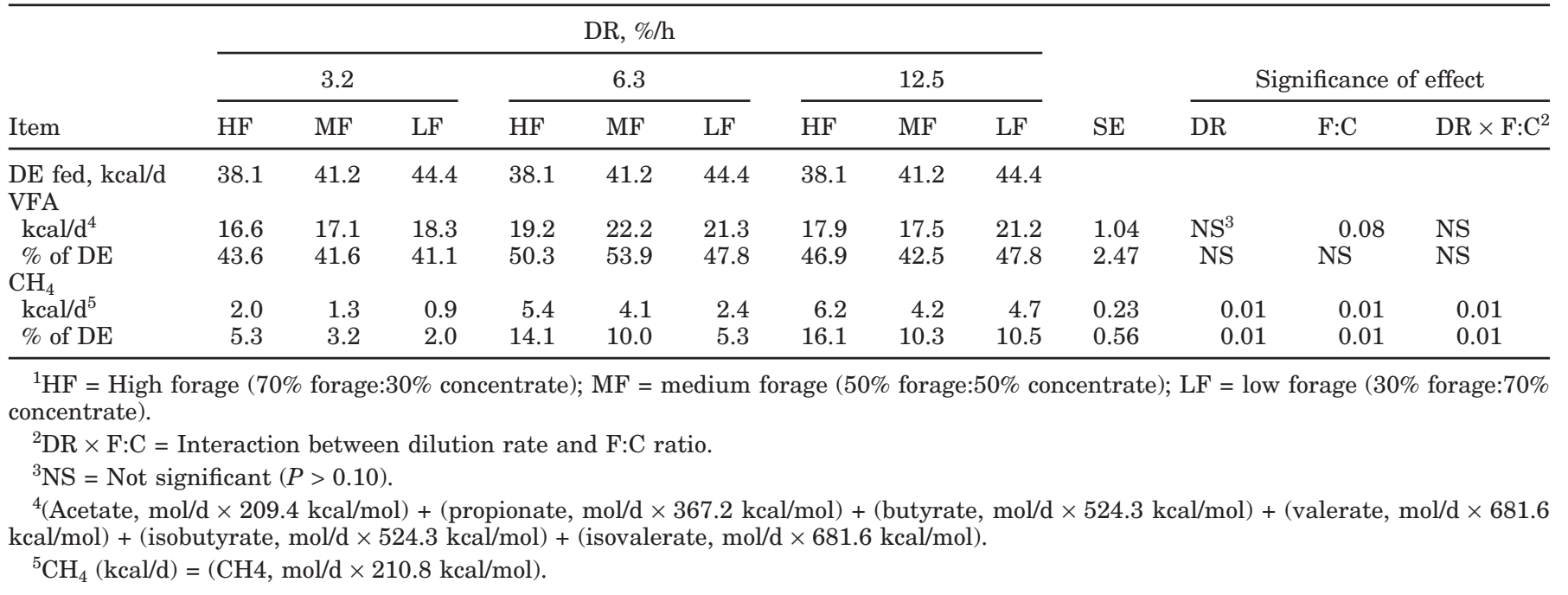

tended to decrease and that of butyrate increased with an increase in dilution rate, but production of both fatty acids remained unchanged. Ruminal $\mathrm{pH}$ and ruminal methane output increased with increasing dilution rate. The effect of dilution rate on VFA production and fermentation profile in other studies has been variable. Total organic acid production decreased (Carro et al., 1995) or increased (Fuchigami et al., 1989) when fractional dilution rates increased. Molar percentages of propionate in ruminal fluid were reported to be higher (Isaacson et al., 1975; Hoover et al., 1984) or lower (Thomson et al., 1978; Crawford et al., 1980) as a result of increasing dilution rates.

In the present study, dilution rate had a significant effect on the isoacids. Rapid liquid turnover lowered the proportion of ruminal valerate but increased that of the branched chain isoacids, isobutyrate, and isovalerate. Part of the valerate produced in the rumen comes from the fermentation of carbohydrates and part comes from the fermentation of AA. The branched-chain isoacids arise almost exclusively from the oxidative deamination of AA. The inability of the cellulolytic bacteria to transport preformed branched chain AA across their cell wall makes the branched chain isoacids essential for normal growth of fiber-digesting bacteria (Bryant, 1973). The decrease in valerate may be due to reduced retention time of the fermentable carbohydrates at higher liquid passage rates. An increase in branchedchain isoacids suggests enhanced deaminative activity at higher dilution rates, since a reduced uptake should have resulted in a lower acetate production.

Increasing liquid turnover increased $\mathrm{NH}_{3}-\mathrm{N}$ output. Ammonia-N concentration, similar to the isoacids, is a function of the rate of release and rate of uptake by microbial populations. Ruminal $\mathrm{pH}$ can also influence $\mathrm{NH}_{3}-\mathrm{N}$ production (Erfle et al., 1982), and increasing dilution rates increased $\mathrm{NH}_{3}-\mathrm{N}$ with a concomitant increase in culture $\mathrm{pH}$ similar to results reported earlier (Hoover et al., 1984). Ammonia-N and branched-chain isoacids increased at higher dilution rates, suggesting either enhanced rate of production or reduced utilization. Both are used predominantly by cellulolytic organisms and, since acetate production was not affected, higher liquid dilution rates seem to have enhanced rates of production rather than reduced rates of utilization.

Similar values for DM digestibility have been reported earlier with no effect on dilution rate (Hoover et al., 1984; Carro et al., 1995). In the study by Hoover et al. (1984), increasing dilution rates did not seem to reduce NDF digestibility or the digestibility of the more rapidly fermentable carbohydrate fraction. In fact, in some cases, increasing dilution rate seemed to increase cellulose and NDF digestibility (Hoover et al., 1984).

Increasing dilution rate did not affect total organic acid production, but actual methane output increased. In contrast, lowering $\mathrm{F}: \mathrm{C}$ ratio reduced methane production and increased ruminal propionate as has been documented in several studies. Increasing dilution rates did not affect the amount of substrate used for VFA production but increased the amount used for gas and microbial biomass. Actual methane production increased significantly at each successive increase in dilution rate, but the proportion of substrate used for total gas output $\left(\mathrm{CH}_{4}+\mathrm{CO}_{2}\right)$ increased only when dilution rates were increased from 3.2 to $12.5 \% / \mathrm{h}$. The growth rate of methanogens is relatively slow, which results in reduced numbers during rapid rates of transit from 
the rumen (Wolin et al., 1997). The highest dilution rate in our study $(12.5 \% / \mathrm{h})$ did not seem to have a negative impact on methane production. Calculated microbial yields and efficiencies increased with an increase in turnover rate suggesting that, at higher turnover rates, a greater proportion of substrate energy is used for bacterial synthesis (Hespell and Bryant, 1979).

According to Wolin (1960), the amount of total gas produced $\left(\mathrm{CH}_{4}+\mathrm{CO}_{2}\right)$ can be determined from the amount and molar proportion of acetate, propionate, and butyrate. Hence, based on the stoichiometric equation, variations in the molar proportion of acetate, propionate, and butyrate will have a direct influence on gas volumes. Blümmel et al. (1997) reported that the total substrate required for the production of equal amounts of gas from widely different VFA patterns was very similar. Accounting for the efficiency of ATP use by microbial populations, the amount of substrate required for microbial biomass can vary without changes in VFA proportions (Blümmel et al., 1997). It is known that the growth yields of ruminal microbes can be relatively high, and that microbial cells have a negative oxidation-reduction state (Van Kessel and Russell, 1996). Since stoichiometric equations used to estimate fermentation balance do not consider microbial cells as end products of ruminal fermentation, cell yields can have a significant impact on estimates of methane production.

The Cornell Net Carbohydrate and Protein System suggests a maximum incorporation of $40 \%$ of the fermented feed carbohydrate into microbial biomass (Russell et al., 1992). With substrates consisting predominantly of structural carbohydrates, microbial biomass yield was negatively correlated to gas production over a 24-h period of incubation (Blümmel et al., 1997). In another study (Krishnamoorthy et al., 1991), a curvilinear relationship was reported over a 2 -h period between microbial protein synthesis and gas production. The curvature varied with the type of substrate, with cellulose producing a steep upward curve and starch producing a less steep curve. The relationship between microbial mass and gas volume is complex and can vary with the type of substrate as well as with the time of sampling.

In previous experiments, no distinction was made between $\mathrm{CO}_{2}$ and $\mathrm{CH}_{4}$, and it is assumed that the latter arises directly from the former. As per the stoichiometric equations outlined previously (Wolin, 1960; Blümmel et al., 1997), we included both the direct $\mathrm{CO}_{2}$ production from the fermentative route as well as the indirect contribution from the reaction of the VFA with the bicarbonate supplied in the saliva in estimating total gas production. Total gas production was not affected by the F:C ratio and dilution rates in the present study.
Methane production, when estimated using stoichiometric equations, was also not altered by either the dilution rates or F:C ratio. However, actual measurements of methane production decreased significantly with an increase in the level of concentrate and increased with an increase in dilution rate. The decrease in methane in cultures receiving a higher proportion of concentrate is consistent with the shift in reducing equivalents toward propionate formation. However, the increased methane formation at higher dilution rates was unexpected.

Gas production and VFA formation are closely related processes, but gas production can vary without any change in total VFA production (Beuvink and Spoelstra, 1992). The amount of gas released indirectly is assumed to be a constant; therefore, the variation is attributed primarily to gas produced directly as an end product of ruminal fermentation. Direct gas production varies with the pattern of VFA and, given the complex nature of mixed feedstuffs and fermentative pathways of microbial metabolism, it can vary considerably. Most species of rumen microbes are capable of fermenting various substrates resulting in similar end products (Hungate, 1966), and some have switched end products depending on their growth rate (Russell and Wallace, 1997).

Hydrogen and $\mathrm{CO}_{2}$ are the major precursors of $\mathrm{CH}_{4}$ formation in the rumen (Hungate, 1967), and most methanogens can utilize these substrates to generate ATP (Thauer et al., 1977). The distribution of methanogenic species in the rumen is not known and whereas some species can occur in high concentration, others may be present in low concentration (Wolin et al., 1997). Methanogens have a slower growth rate compared with other rumen bacteria, but there are some species, Methanobrevibacter spp. in particular, that will grow more rapidly with $\mathrm{H}_{2}$ than other methanogens (Wolin et al., 1997). The success of microorganisms to survive depends on their ability to maximize growth rate or growth yield (Neijssel and de Mattos, 1994; Russell and Wallace, 1997). Culture of Methanobacter thermoautotrophicum did not grow when $\mathrm{H}_{2}$ supply was low, but they continued to produce methane. At higher availability of $\mathrm{H}_{2}$, growth of $M$. thermoautotrophicum occurred, but methanogenesis remained constant as long as growth was $\mathrm{H}_{2}$ limiting (Morgan et al., 1997). When $\mathrm{H}_{2}$ supply was not growth limiting, $\mathrm{CH}_{4}$ production increased rapidly (Morgan et al., 1997). Changing dilution rates has a profound impact on the growth rate of bacteria and alters the metabolic pathways of fermentation. Given the complex interactions between microbial growth and fermentation environment, altering dilution rates could interfere with growth by changing the concentration and/or shifting the metabolic pathways 
by which specific microbes, including the methanogens, utilize substrates.

\section{CONCLUSIONS}

Methane production in continuous cultures was measured to determine whether it was altered by dilution rate and F:C ratio. Increasing dilution rate or the level of forage in the diet decreased propionate and increased methane output. Methane production estimated from stoichiometric equations remained unchanged, irrespective of the dilution rate or level of forage in the diet. Compared with actual measurements of methane concentration in fermentor headspace, stoichiometric estimations consistently underestimated methane output at higher dilution rates and with high forage diets. Methane production seems to be influenced by the stoichiometry of substrate fermentation to acetate and propionate as well as the proportion of substrate carbon fixed in microbial biomass.

\section{ACKNOWLEDGMENTS}

The expertise offered by Sarah Jo McLeod for her assistance in the lab is gratefully acknowledged. The authors also appreciate the financial support provided by the Dairy Foundation of North Carolina.

\section{REFERENCES}

Beecher, G. R., and B. K. Whitten. 1970. Ammonia determination: Reagent modification and interfering compounds. Anal. Biochem. $36: 243-246$

Beuvink, J. M. W., and S. F. Spoelstra. 1992. Interactions between substrate, fermentation end-products, buffering systems and gas production upon fermentation of different carbohydrates by mixed rumen microorganisms in vitro. Appl. Microbiol. Biotechnol. 37:505-509.

Blümmel, M., H. P. S. Makkar, and K. Becker. 1997. In vitro gas production: A technique revisited. J. Anim. Physiol. 77:24-34.

Bryant, M. P. 1973. Nutritional requirements of the predominant rumen cellulolytic bacteria. Fed. Proc. 32:1889-1913.

Carro, M. D., P. Lebzien, and K. Rohr. 1995. Effects of pore size of nylon bags and dilution rate on fermentation parameters in a semi-continuous artificial rumen. Small Ruminant Res. 15:113-119.

Crawford, R. J., Jr., W. H. Hoover, and P. H. Knowlton. 1980. Effects of solids and liquid flows on fermentation in continuous cultures. I. Dry matter and fiber digestion, VFA production and protozoa numbers. J. Anim. Sci. 51:975-985.

Doane, P. H., P. Schofield, and A. N. Pell. 1997. Neutral detergent fiber disappearance and gas and volatile fatty acid production during the in vitro fermentation of six forages. J. Anim. Sci. 75:3342-3352.

El-Din, M. Z., and K. El-Shazly. 1969. Evaluation of a method of measuring fermentation rates and net growth of rumen microorganisms. Appl. Microbiol. 17:801-804.

Erfle, J. D., R. J. Boila, R. M. Teather, S. Mahadevan, and F. D. Sauer. 1982. Effect of $\mathrm{pH}$ on fermentation characteristics and protein degradation by rumen microorganisms in vitro. 65:1457-1464.
Fuchigami, M., T. Senshu, and M. Horiguchi. 1989. A simple continuous culture system for rumen microbial digestion study and effects of defaunation and dilution rates. J. Dairy Sci. 72:3070-3078.

Groot, J. C., B. A. Williams, A. J. Oostdam, H. Boer, and S. Tamminga. 1998. The use of cumulative gas and volatile fatty acid production to predict in vitro fermentation kinetics of Italian ryegrass leaf cell walls and contents at various time intervals. Br. J. Nutr. 79:519-525.

Hespell, R. B., and M. P. Bryant. 1979. Efficiency of rumen microbial growth: Influence of some theoretical and experimental factors on $\mathrm{Y}_{\text {AтP. }}$ J. Dairy Sci. 49:1640-1659.

Hoover, W. H., C. R. Kincaid, G. A. Varga, W. V. Thayne, and L. L. Junkins, Jr. 1984. Effects of solids and liquid flows on fermentation in continuous cultures. IV. $\mathrm{pH}$ and dilution rate. J. Anim. Sci. 58:692-699.

Hungate, R. E. 1966. Quantities of carbohydrate fermentation products. Pages 245-280 in The Rumen and Its Microbes. Academic Press, New York, NY.

Hungate, R. E. 1967. Hydrogen as an intermediate in the rumen fermentation. Arch. Microbiol. 59:158-164.

Isaacson, H. R., F. C. Hinds, M. P. Bryant, and F. C. Owens. 1975. Efficiency of energy utilization by mixed rumen bacteria in continuous culture. J. Dairy Sci. 58:1645-1659.

Krishnamoorthy, U., H. Steingass, and K. H. Menke. 1991. Preliminary observations on the relationship between gas production and microbial synthesis in vitro. Arch. Anim. Nutr. (Berlin) 41:521-526.

Menke, K. H., L. Raab, A. Salewski, H. Steingass, D. Fritz, and W. Schneider. 1979. The estimation of the digestibility and metabolizable energy content of ruminant feedingstuffs from the gas production when they are incubated with rumen liquor in vitro. J. Agric. Sci. 93:217-222.

Menke, K. H., and H. Steingass. 1988. Estimation of the energetic feed value obtained from chemical analysis and in vitro gas production using rumen fluid. Anim. Res. Dev. 28:7-55.

Miller, T. L. 1995. Ecology of methane production and hydrogen sinks in the rumen. Pages 317-331 in Ruminant Physiology: Digestion, Metabolism, Growth, and Reproduction. E. V. Engelhardt, S. Leonhard-Marek, G. Breves, and D. Giesecke, eds. Ferdinand Enke Verlag, Stuttgart, Germany.

Morgan, R. M., T. D. Pihl, J. Nölling, and J. N. Reeve. 1997. Hydrogen regulation of growth, growth yields, and methane gene transcription in Methanobacterium thermoautotrophicum Delta H. J. Bacteriol. 179:889-898.

Naga, M. A., and J. H. Harmeyer. 1975. Gas and volatile fatty acid production at different rates of rumen microbial protein synthesis in vitro. J. Dairy Sci. 40:374-379.

National Research Council. 1989. Nutrient Requirements of Dairy Cattle. 6th rev. ed. Natl. Acad. Sci., Washington, DC.

Neijssel, O. M., and M. J. T. de Mattos. 1994. The energetics of bacterial growth: a reassessment. Mol. Microbiol. 13:179-182.

Pell, A. N., and P. Schofield. 1993. Computerized monitoring of gas production to measure forage digestion in vitro. J. Dairy Sci. 76:1063-1073.

Raab, L. 1980. Untersuchungen über den proteinabbau und die proteinsynthese im künstlichen pansen. Ph.D. Dissertation. University of Hohenheim, Stuttgart, Germany.

Russell, J. B., and R. L. Baldwin. 1979. Comparison of maintenance energy expenditures and growth yields among several rumen bacteria grown on continuous culture. Appl. Environ. Microbiol. $37: 537-543$

Russell, J. B., J. D. O’Connor, D. G. Fox, P. J. Van Soest, and C. J. Sniffen. 1992. A net carbohydrate and protein system for evaluating cattle diets: I. Ruminal fermentation. J. Anim. Sci. 70:3551-3561.

Russell, J. B., and R. J. Wallace. 1997. Energy-yielding and energyconsuming reactions. Pages 246-282 in The Rumen Microbial Ecosystem. 2nd ed. P. N. Hobson and C. S. Stewart, ed. Blackie Academic \& Professional, New York, NY.

SAS Proprietary Software, Version 8. 1999. SAS Inst., Cary, NC. 
Slyter, L. L., M. P. Bryant, and M. J. Wolin. 1966. Effect of pH on population and fermentation in a continuously cultured rumen ecosystem. Appl. Microbiol. 14:573-578.

Steel, R. G. D., J. H. Torrie, and D. A. Dickey. 1997. Analysis of variance IV: Split-plot designs and analysis. Pages 400-428 in Principles and Procedures of Statistics. A Biometrical Approach. 3rd ed. McGraw-Hill Co., New York, NY.

Taya, M., K. Ohmiya, T. Kobayashi, and S. Shimizu. 1980. Monitoring and control of a cellulolytic anaerobe culture by using gas evolved as an indicator. J. Ferment. Technol. 5:463-469.

Teather, R. M., and F. D. Sauer. 1988. A naturally compartmented rumen simulation system for the continuous culture of rumen bacteria and protozoa. J. Dairy Sci. 71:666-673.

Thauer, R. K., K. Jungermann, and K. Decker. 1977. Energy conservation in chemotriphic anaerobic bacteria. Bacteriol. Rev. $41: 100-180$

Theodorou, M. K., R. S. Lowman, Z. S. Davies, D. Cuddeford, and E. Owen. 1998. Principles of techniques that rely on gas measurement in ruminant nutrition. Pages 55-63 in In Vitro Techniques for Measuring Nutrient Supply to Ruminants. British Soc. Anim. Sci. Occasional Publ. No. 22. Reading, UK.

Thomson, D. J., D. E. Beever, M. J. Latham, M. E. Sharpe, and R. A. Terry. 1978. The effect of inclusion of mineral salts in the diet on dilution rate, the pattern of rumen fermentation and the composition of the rumen microflora. J. Agric. Sci. (Camb.). 91:1-7.

Van Kessel, J. S., and J. B. Russell. 1996. The effect of $\mathrm{pH}$ on ruminal methanogenesis. FEMS Microbiol. Ecol. 20:205-210.

Van Nevel, C. J., and D. I. Demeyer. 1977. Determination of rumen microbial growth in vitro from ${ }^{32} \mathrm{P}$-labelled phosphate incorporation. Br. J. Nutr. 38:101-114.

Van Soest, P. J. 1994. Microbes in the gut. Pages 253-280 in Nutritional Ecology of the Ruminant. 2nd ed. Cornell Univ. Press, Ithaca, NY.

Wolin, M. J. 1960. A theoretical rumen fermentation balance. J. Dairy Sci. 43:1452-1459.

Wolin, M. J., T. L. Miller, and C. S. Stewart. 1997. Microbe-microbe interactions. Pages 467-491 in The Rumen Microbial Ecosystem. 2nd ed. P. N. Hobson and C. S. Stewart, eds. Blackie Academic \& Professional, New York, NY. 